\title{
RESEARCH ON THEMATIC MAPS IN THE NEW CENTURY EDITION OF THE NATIONAL GEOMATICS ATLAS OF THE PEOPLE'S REPUBLIC OF CHINA
}

\author{
ZHAO Tingting $^{1} *$, WANG Donghua ${ }^{1}$, LIU Wanzeng ${ }^{1}$, ZHU Xiuli ${ }^{1}$, CHEN Mian ${ }^{2}$, WANG Guizhi ${ }^{1}$, ZHOU Wen $^{3}$, MA Wei ${ }^{4}$ \\ ${ }^{1}$ National Geomatics Center of China, Beijing 100830, China - zhaotingting@ngcc.cn \\ ${ }^{2}$ Chinese Academy of Surveying and Mapping, Beijing 100830, China \\ ${ }^{3}$ Heilongjiang Administration Surveying, Mapping and Geoinformation, Haerbin 150086, China \\ ${ }^{4}$ National Quality Inspection and Testing Center for Surveying and Mapping Products, Beijing 100830, China
}

KEY WORDS: Thematic Map, Map Compilation, Thematic Map Selection, Map Design, Technical Process

\begin{abstract}
:
The National Geomatics Atlas is the first volume of the new century edition of the National Huge Atlas of the People's Republic of China, and is one of the important achievements of this research and development project. The National Geomatics Atlas consists of four thematic map groups and one place name index, such as the sequence map group, the political terrain map group, the land cover map group and the city map group. The research object of this paper is the thematic maps, which are mainly distributed in the sequence map group, the land cover map group and the city map group. This paper is aimed at the design and compilation of thematic maps, including a brief introduction of thematic maps selection, layout design, thematic map technical process, and thematic symbol design.
\end{abstract}

\section{INTRODUCTION}

The National Geomatics Atlas is the first volume of the new century edition of the National Huge Atlas of the People's Republic of China, and is one of the important achievements of this research and development project. The National Geomatics Atlas comprehensively displays the basic geographic information content of China, and displays in more detail the distribution of basic elements such as hydrology, topography, residential areas, transportation, political areas, and soil vegetation closely related to economic society and people's livelihood. It is an important basic information for comprehensively understanding the status and level of China's development, and it is also a well-documented tool for researchers, educators and readers to understand the current situation of China's geography and popularize all aspects of knowledge.

The National Geomatics Atlas consists of four thematic map groups and one place name index, such as the sequence map group, the political terrain map group, the land cover map group and the city map group. The research object of this paper is the thematic maps of the National Geomatics Atlas, which are mainly distributed in the sequence map group. There are several thematic maps distributed in the land cover map group and the city map group.

This paper is aimed at the design and compilation of thematic maps, including a brief introduction of thematic maps selection, structural design, layout design, thematic map technical process, and thematic symbol design.

\section{RESEARCH ON THE DESIGN OF THEMATIC MAPS}

The thematic maps are mainly overview maps. The main part of the thematic maps are the national general maps of the ordinary map elements. They provide a comprehensive introduction to China's geographical overview and construction achievements, and both natural geography and human geography.

\subsection{The Design of Thematic Maps Selection}

When selecting the data, thematic maps mainly select the thematic factor data closely related to the theme of the atlas. For example, according to the national macro development strategy, the Belt and Road regional information is selected to reflect its natural geography; according to the national strategy of building a marine power, the special information of China's sea area is selected to highlight the relationship between seabed topography and land and sea, emphasizing the importance of the ocean.

According to the national rapid transit network development strategy, high-speed railway and highway special information are selected. In order to reflect China's valuable natural and cultural resources, the thematic maps select a series of special information such as nature reserves, forests, geological parks, world cultural and natural heritage, national-level scenic spots, land cover, historical and cultural cities, etc., to reflect the harmonious development of people and nature. In order to reflect the spatial distribution of China's cities and the

\footnotetext{
* Corresponding author: zhaotingting@ngcc.cn
} 
development process of urbanization in China, the thematic maps select thematic information such as urban spatial location, population size, GDP size, and historical and cultural evolution.

There are mainly twenty-three maps in the thematic maps, including eighteen maps of the sequence map group, a map of the land cover map group and four maps of the city map group. Thematic maps include World Political District, World Topography, Belt and Road Initiative, China's Administrative Region, China's Topography, China's Seas, China's Image, China's Water System, China's Railway, China's Highway, China's Airport and Port, China's Population, China's Tourism Resources, China's Geology Parks, China's Nature Reserves, China's Forests, China's Geography National Conditions, China's Geography National Statistics, China's Surface Coverage, China's Cities, China's Urbanization, Famous Cities in China, China's Urban Agglomerations and Strategic Layout.

\subsection{The Design of Thematic Maps Layout}

The layout of the thematic map is more flexible. If a thematic map can be represented in a single map, it should be treated like a normal geographic map. If the content of a topic requires multiple map representations, arrange it in one or several map formats as needed.

The thematic maps in the National Geomatics Atlas mainly adopt two forms of unfolding page core and half-page core. Except for China's Geography National Conditions and China's Geography National Statistics, the others are the core of the page.

The thematic maps adopt two maps of rectangular map and island map. The rectangular map is used when the content of the main area is related to the neighboring area. Where the content of the main area is not related to the neighboring area (or has little relationship with the neighboring area) and the content is relatively simple, the island map is adopted. At the same time, the thematic maps are accompanied by charts and photographs, and a small amount of text descriptions are added to make the maps appear active, novel and beautiful, while keeping the drawings neat and correct.

Most of the thematic maps in the National Geomatics Atlas are in the form of rectangular maps. There are only four maps on the island map. It is the world political region, the world topography, the status quo of China's geography and the national statistics of China's geography.

The island maps only have the four maps of the World Political District, the World Topography, the National Conditions of China's Geography, and the National Statistics of China's Geography.

\subsection{The Design of Thematic Maps Graphic}

The graphics of the thematic maps mainly include distribution maps, statistical graphs, contour maps and type maps, which are compiled by two levels: geographic base map and thematic elements. The geographical base map is based on the National Basic Geographic Information Data, and selects appropriate political districts, roads, water systems, annotations and other layers. On the basis of the geographical base map, the thematic elements are classified and hierarchically represented according to thematic categories and feature geometric features, and generally contain 20 types of topics and more than 40 data layers.

The charts and symbols in the thematic maps use stereoscopic representations, and use light and shadow effects, color mixing transitions, such as illuminated cylinders and solid square columns, photos plus solid shadows, and raw edges to increase the perceived effect and appeal of the thematic map.

The thematic maps represent a wide range of content, including maps, contour maps, type maps, zoning maps, and statistical graphs. There are more than ten representation methods. However, for a thematic map, one or two representations are the main methods, and several other methods are supplemented.

\subsection{The Design of Thematic Maps Symbol}

The map symbol is the first language of the map. The design of the thematic map symbol needs to summarize and abstract the added thematic features based on the basic map elements, and express them with specific symbols.

The design of the thematic map symbol has a higher comprehensiveness to the map design. Through the various symbol design, the theme content is expressed, and the theme is beautiful and clear.

The symbols in the thematic maps are mostly in the form of three-dimensional symbols, which are in sharp contrast with the map bottom map, and at the same time increase the visual experience of the thematic map to achieve a more vivid expression of the theme.

\section{THEMATIC MAP COMPILATION TECHNICAL PROCESS}

The thematic map compilation technical process mainly includes data processing, map editing and map finishing, etc. Firstly, the geographic base map and the thematic data processing are performed, and then the projection data, the scale setting, the data cutting and the like are formed to form the drawing data. According to the design and editing requirements of the thematic map, the process of drawing data editing, symbol replacement, annotation configuration, color adjustment, comprehensive selection, relationship coordination, etc., finally loading the frame decoration, and the thematic maps of different scales are generated.

The first step is data processing.

Firstly, according to the projection design requirements of the national thematic map, the projection transformation is performed based on the thematic map database, and then the scale is set according to the size of the drawing area and the size of the core, and the cutting frame is determined, and the drawing area is basically at the center position, and the north is Orientation. Then the frame is cut, the data is extracted, and the format is converted to form the cartographic data with strict mathematical foundation and complete elements. 
The next step is map editing.

Then, according to the design and editing requirements of the national thematic map, the above-mentioned drawing data is subjected to thinning smoothing, editing processing, symbol replacement, annotation configuration, color adjustment, comprehensive selection, relationship coordination, and layer adjustment.

The final step is the map decoration.

Finally, the frame is decorated, and the name and page number are modified to form a full-scale thematic map of different scales. After inspection and acceptance, the PDF pre-press data is output.

\section{CONCLUSIONS}

The new century edition of the National Geomatics Atlas of the People's Republic of China is based on detailed and reliable National Basic Geographic Information Data for research and development, data authority, complete content, expression norms, and thematic series, which can comprehensively display China's geographical conditions in a multi-faceted and multiperspective manner.

The thematic maps in the National Geomatics Atlas are a series of ordinary maps reflecting the general picture of the country. They reflect the distribution of the natural environment, social development and economic construction elements in China. They are an important information platform for serving the country and helping macro-decision. They will provide an important basis for macroeconomic decision-making such as economic policy formulation, long-term planning, and rational allocation of productivity.

\section{ACKNOWLEDGEMENTS}

This work is partly supported by National Key R\&D Program of China (No. 2018YFC0807005).

\section{REFERENCES}

CHEN, Y., 2005. A Research into Contemporary Atlas Design. Science Press, China.

DU, X.R., TANG, J.J., and LIAO, J.J., 2011. China Atlas (2nd Edition). China Map Publishing House, China.

LU, Y.S., 1997. National General Atlas Editing Design Features. Cartography, (04), pp. 22-24.

Ministry of Science and Technology, 2013. The Project Plan Task Book of New Century Edition National Huge Atlas of the People's Republic of China. Ministry of Science and Technology, China.
National Geomatics Center of China, the editorial department of National Geomatics Atlas, 2015. The overall design scheme of new century version of the National Geomatics Atlas of the People's Republic of China.

WANG, G.Z., WANG, D.H., ZHOU, W., CHEN, M., ZHAO, T.T., and FENG, Y., 2018a. Research And Compilation of City Maps in New Century Edition of "National Geomatics Atlas of the People's Republic of China". Geomatics World, 25(04), pp. 80-85.

WANG, G.Z., WANG, D.H., ZHOU, W., CHEN, M., and ZHAO, T.T., 2018b. The Research and Compilation of City Maps in the National Geomatics Atlas of the People's Republic of China. ISPRS Archives. Photogramm. Remote Sens. Spatial Inf. Sci., XLII-3, 1703-1706. doi.org/10.5194/isprs-archivesXLII-3-1703-2018.

ZHAO, T.T., and LIU, W.Z., 2018a. Research on the Refinement and Efficient Decision-making Map Compilation Based on MAPublisher. Geomatics World, 25(03), pp. 87-90.

ZHAO, T.T., LIU, W.Z., and MA, W., 2018b. Research and Practice of the News Map Compilation Service. ISPRS Archives. Photogramm. Remote Sens. Spatial Inf. Sci., XLII-3, 2407-2410. doi.org/10.5194/isprs-archives-XLII-3-2407-2018. 